preparations used in treating wonnds ; (2) in its concentrated form it is an excellent substitute for nitric acid and nitrate of silver; it is especially superior to phenic acid, because it has not got its extremely disagreeable odor; (3) in aqueous solution ( 1 in 1000), to which a few grammes (a gramme is equal to 15.4 grains) of alcohol have beeu added; it is extremely useful in furthering the cicatrization of wounds. It is especially serviceable in those cases in which tincture of iodine is generally employed.-The Practitioner, Nov. 1868.

23. Employment of Glycerine of Tannin.-Dr. Sidney Rinaer, in an interesting paper (The Practitioner. July, 1868), says that this preparation of tannin appears to be but little known, while in his opinion it is very serviceable in many diseases. In this country it is perhaps even less known. We do not find it mentioned in the U.S. Dispensatory; but on reference to a very recent English work (Dictionary of Mat. Med. and Ther., by Adolph Wahltuch, M. D.), we find the following formula for its preparation: R.-Gallic acid, $\mathbf{z j}$; Glycerine, fziv. Rub and heat. Dr. R. thinks this preparation of great use in ozena; in the thin sanious or thicker purulent discharge from the nostrils which sometimes occurs after measles, scarlatina, and other diseases; in the obstruction of the nose freqnent in syphilitic children. The thin, sanious or purulent discharge from the ears, so commonly met with in unhealthy children, can, he says, be stopped at once by filling np the external meatus with this preparation. If there be acute inflammation of the meatus, this should be relieved before using the tannin.

In many cases of eczema he says this preparation is of very great use. "It is of service only in the earlier stages of the disease. Thus, when the skin is inflamed, red, swollen, and weeping, if the scabs be thoroughly removed, and the raw surface be painted over with this preparation of tannin, the discharge is stayed, the redness, heat, and swelling much lessened or removed, and the appearance of the parts much improved. When in a less active condition, and when the tissues are less red, swollen, and weeping, the eczema may more profitably be treated in the same way. 'The tissues assume a much healthier appearancc, and after a few applicatious look like a healthy, healing sore. A poultice may be usefully applied at night, and this glycerine of tannin twice or three times in the day. All the advantages which accrue from its employment in this disease have not jet been mentioned, for the troublesome itching, and tingling, and bnrning, so common in eczema, are at once removed by this application, and thus the tearing with the nails and rubbing with the hands which prevents the healing of the sore, and causes it even to spread, is prevented, and the comfort and well-doing of the patient much promoted, as the itchiug and feeling of bn rning often greatly breaks the sleep. Sometimes the glycerine of tannin does not, of itself, quite remove the disease, but brings it to the stage where there is only a little desquamation; with a tendency to erack and ooze. It may be necessary in sueh case to perfect the cure by a resort to tar or carbolic acid ointment. It need not be said that some cases prove incurable by this as by all other treatment. Impetigo may be beneficially treated in the same way. The scabs should be removed by a ponltice applied each night, while this tannin preparation is employed during the day. In the treatment of thcse diseases of the skin by this application, the state of the digestive organs must not be overlooked, bnt anything wrong with them should, if possible, be removed.

"The eczema which occurs behind the ears of children, and is often limited to these places, is most admirably treated with the remedy. It almost always dries up and heals after one or two applications, even when it has lasted for weeks or for months. The gums. if red and swollen, shnuld be lanced, or other irritations removed. Intertrigo of children may also be treated in this way."

He thinks it an extremely useful application to the throat in chronic inflammation and in superficial ulceration of the pharyngeal mucous membrane, and when this membrane is relaxed, moist, and granular looking, etc.

24. New Method of Applying Remedies to the Pharynx and Larynx by Means of Irrigation.-Prof. Merket, of Leipzig. rend a paper on this subject befo:e No. CXIII.—JAN. 1869. 
the recent annual congress of naturalists and physicians. This method was practised in the following manner: The patient took half a teaspoonful of the liquid to be used, the head being retroflexed and the mouth wide open; lct it fluw down the tongue, and then made some lateral movements with the head, in order to bring the liquid into contact with all the parts upon which it was intended to act. The Professor showed, by an auto-laryngoscopic demonstration, that, by operating in this manner, the liquid would touch the base of the tongue, the sinus glosso-epiglotticus, the anterior portion of the epiglottis. the hyo-epiglottic ligament, the pyriform sinuscs, the posterior surface of the arytenoid cartilages, and the posterior wall of the glottis cartilaginea. The method was useful in all congestive and inflammatory conditions of the mucous membranes of the pharynx connected with difficulty of swallowing, retching, sickness, etc., also in erosions, ulcers, and other lesions of the same parts, in infiltration, tumonrs, and paralysis of the muscles on the posterior part of the arytenoid cartilage. Tannin was the remedy chiefly used by the Professor, but he also sometimes employed nitratc of silver, iron, iodine, morphia, nux vomica, Calabar bean, etc.-Med. Times and Gaz., Nov. 28, 1868 .

25. Portable Mustard Plasters.-M. Lenatgne (Journal de Pharmacie) has proposed to make portable mustard plasters in the following manner: He covers one piece of paper with a concentrated solution of myronate of potash, and a second with a concentrated solution of myrosine. When the two papers are moistened and put together the essence of mustard is developed. The solution of myronate of potash is obtained by throwing into boiling water the farina of black mustard. The filtered solution contains the myronate of potash, as the boiling water has destroyed the action of the myrosine. 'The myrosine is obtained by action apon white mnstard by water at $40^{\circ} \mathrm{C}$. T'he filtered solution will contain nothing but the myrosine, as white mustard does not contain myronate of potash.-Med. Press and Circular, Nov. 1868.

\section{MEDICAL PATHOLOGY, SPECIAL THERAPEUTICS, AND PRACTICE OF MEDICINE.}

26. New Investigations relative to the Pathology of Cerebral Hemorrhage. -MM. Charcot and Bouchand have published (Archives de Physiologic: Normale et Patholoyique, Nos. 1, 5, and 6, 1868) a very interesting memoir on this subject.

Of 84 cases of cerebral hemorrhage which they have collected, in every one miliary aneurisms existed.

Other anatomical conditions which have been supposed to exert an influence in the production of cerebral hemorrhage were met with, but less frequently.

Thus, atheroma of the arteries of the brain, to which has been ascribed a preponderating inflnence, is shown by MM. C. and B.'s statistics not to hold the first place. The state of the arteries at the base of the brain was noticed in 69 cases. Of this number the arteries were not atheromatous 15 times, or in more than a fifth of the cases; they were very slightly or scarcely at all atheromatous in 25 cases, or in more than a third of the cases; they were recorded as simply atheromatous in 12 cases; finally, they were very atheromatons in 17 cases, or in scarcely one-fonrth of the cases. We may be permitted, then, to assert that subjects who die of cerebral hemorrhage have the arteries of the brain non-atheromatous in less than a fourth of the cases, or nearly 22 per cent., and that these latter prescnt different degrees of atheroma in scarcely three-fourths of the cases. This frequency of the apparent integrity of the arteries of the brain in subjects who present old or reccnt spots of sanguineous effusion does not accord with admitted opinions, and this result differs very considerably from the figures obtained in former statistics. M. Durand Fardel, 